\title{
PARÂMETROS IMUNOLÓGICOS E INFECÇÕES DO TRATO RESPIRATÓRIO SUPERIOR EM ATLETAS DE ESPORTES COLETIVOS
}

IMMUNOLOGICAL PARAMETERS AND UPPER RESPIRATORY TRACTINFECTIONS IN TEAM SPORTS ATHLETES

Artigo de Revisão

REVIEW ARTICLE

PARÁMETROS INMUNOLÓGICOS EINFECCIONES DEL TRACTO RESPIRATORIO SUPERIOR EN ATLETAS DE

ARTÍCULO de ReVISIÓN

DEPORTESDE EQUIPO

\begin{abstract}
Rodrigo Dias ${ }^{1}$
(Profissional de Educação Física)

Ronaldo Júlio Baganha

(Profissional de Educação Física)

Fabricio Cieslak ${ }^{2}$

(Profissional de Educação Física)

Kleverton Krinski ${ }^{2}$

(Profissional de Educação Física)

Nathália Ferreira Camarço ${ }^{3}$

(Profissional de Educação Física)

Rozangela Verlengia' (Bióloga)

Charles Ricardo Lopes

(Profissional de Educação Física)

Jonato Prestes ${ }^{3}$

(Profissional de Educação Física)

Carlos Alberto da Silva' (Biólogo)

Cláudia Regina Cavaglieri ${ }^{4}$

(Farmacêutica)
\end{abstract}

1. Universidade Metodista de Piracicaba (UNIMEP), Piracicaba, SP, Brasil.

2. Universidade Federal do Vale do São Francisco (UNIVASF), Petrolina, PE, Brasil.

3. Universidade Católica de Brasília (UCB), Brasília (DF), Brasil.

4. Universidade Estadual de Campinas (UNICAMP), Faculdade de Educação Física, Departamento de Estudos da Atividade Física Adaptada, Laboratório de Fisiologia do Exercício, Campinas, SP, Brasil.

\section{Correspondência:}

R. Minas Gerais, 1259, Jardim Alice, Jaguariúna, SP, Brasil. 13820-000. rdiasd@gmail.com

\section{RESUMO}

Entre atletas e treinadores, existe uma percepção comum de que altas cargas de treinamento e competições, aplicadas de forma crônica, com controle nutricional e/ou períodos de recuperação inadequados, podem reduzir a resistência imunológica, aumentando a predisposição aos episódios de infecções, principalmente infecções do trato respiratório superior (ITRS). Nesse sentido, o presente estudo está centrado em revisar as interações entre os parâmetros imunológicos com a síndrome do sobretreinamento, especificamente em esportes coletivos, considerando a sua natureza intermitente. Assim, foi realizada uma revisão de periódicos nacionais e internacionais relacionados com o tema. As correlações entre exercício, sistema imunológico e suscetibilidade às ITRS têm sido avaliadas principalmente em esportes individuais e de resistência em comparação aos coletivos. As modulações dos leucócitos ao longo da temporada, frente ao efeito somatório das cargas de treinamento e competições, quando analisadas especificamente quanto aos neutrófilos e monócitos, possivelmente se relacionam com os processos de reparo tecidual e incidência de ITRS. As modulações relacionadas com os linfócitos parecem estar relacionadas mais diretamente com a incidência das ITRS. Ademais, o entendimento de todos os marcadores propostos, incluindo os imunológicos em associação com os indicadores de desempenho e controle do treinamento, parece ser um caminho mais promissor para o diagnóstico clínico do estado imunológico do atleta e da prevenção da síndrome do sobretreinamento do que necessariamente a busca por um marcador exclusivo de excesso de treinamento.

Descritores: alergia e imunologia; infecções respiratórias; exercício; medicina esportiva.

\section{ABSTRACT}

Among athletes and coaches, there is a common perception that high training loads and competitions, applied chronically, with inadequate nutritional control and/or recovery periods, may reduce the immune resistance, increasing susceptibility to infection episodes, mainly upper respiratory tract infection (URTI). In this sense, this study is focused on reviewing the interactions between immunological parameters with the overtraining syndrome, specifically in team sports, considering its intermittent nature. Thus, a review of national and international journals related to the topic was held. The correlations between exercise, immune system and susceptibility to URTI have been evaluated mainly in individual and endurance sports compared to the team sports. The modulations of leukocytes throughout the season, against the totalization of training loads and competitions, when analyzed specifically for neutrophils and monocytes, are possibly related to tissue repair processes and incidence of URTI. Modulations related to lymphocytes seem to be more directly related to the incidence of URTI. Moreover, an understanding of all the proposed markers, including immunological markers, in association with the performance indicators and control of training, appears to be a more promising avenue for clinical diagnosis of the athlete's immune status and prevention of overtraining syndrome than the search for a unique marker of overtraining.

Keywords: allergy and immunology; respiratory tract infections; exercise; sports medicine.

\section{RESUMEN}

Entre los atletas y entrenadores, hay una percepción común de que las altas cargas de entrenamiento y competiciones, aplicados crónicamente, con períodos de controly/o de recuperación nutricional inadecuados, pueden reducir la resistencia inmunológica, aumentando la susceptibilidad a los episodios de infecciones, especialmente del tracto respiratorio superior (ITRS). En este sentido, el presente estudio está centrado en la revisión de las interacciones entre los parámetros inmunológicos con el síndrome de sobreentrenamiento, sobre todo en los deportes de equipo, teniendo en cuenta su naturaleza intermitente. Por lo tanto, se llevó a cabo una revisión de revistas nacionales e internacionales relacionadas con el tema. Las correlaciones entre el ejercicio, el sistema inmunológico y la susceptibilidad a la ITRS han sido evaluadas sobre todo en deportes individuales y de resistencia en comparación con los deportes colectivos. Las modulaciones de leucocitos durante la temporada, con relación al efecto de la suma de las cargas de entrenamiento y competiciones, cuando analizadas específicamente con relación a los neutrófilos y los monocitos, posiblemente están asociadas a los procesos de reparación de tejidos y la incidencia de la ITRS. Las modulaciones relacionadas con los linfocitos parecen estar asociadas más directamente a la incidencia de la ITRS. Además, la comprensión de todos los marcadores propuestos, incluyendo los inmunológicos en asociación con los indicadores de rendimiento y 
el control del entrenamiento parece ser una vía más prometedora para el diagnóstico clínico del estado inmunológico del atleta y para la prevención del síndrome de sobreentrenamiento que necesariamente la búsqueda de un único marcador de sobreentrenamiento.

Descriptores: alergia e inmunología; infecciones del sistema respiratorio; ejercicio; medicina deportiva.

\section{INTRODUÇÃO}

Entre atletas e treinadores, existe uma percepção comum de que altas cargas de treinamento e competições, aplicadas de forma crônica, com inadequado controle nutricional e/ou períodos de recuperação, podem reduzir a resistência imunológica, aumentando a predisposição aos episódios de infecções, principalmente infecções do trato respiratório superior (ITRS), sendo tal percepção, consistente com a literatura científica ${ }^{1-8}$.

Evidências científicas indicam que o exercício apresenta efeitos ambíguos sobre o sistema imunológico, correlacionando-o com diminuições nos episódios de ITRS quando realizado regularmente em intensidades e volumes moderados ${ }^{1,3,4,8-11}$.

Antagonicamente, o exercício pode levar a um quadro imunossupressor, com aumentos nos episódios de ITRS, caso executado intensamente e/ou por períodos prolongados que extrapolem as limitações físicas dos atletas ou quando o período de recuperação é insuficiente ${ }^{1-13}$.

Os aumentos nos episódios de ITRS tem relação com: aumentos nas contagens dos neutrófilos e diminuição nos linfócitos circulantes ${ }^{1,14}$; redução da proliferação dos linfócitos e na citotoxicidade das células Natural Killers (NK)1,13,14; aumento da apoptose dos linfócitos 1,13; redução da imunidade da mucosa, em decorrência de diminuições nas concentrações séricas de anticorpos específicos, principalmente a imunoglobulina (lg)- $\mathrm{A}^{1,3,7,15}$ e aumentos nas concentrações séricas das citocinas pró-inflamatórias, principalmente interleucina (IL)-1ß, IL-6 e fator de necrose tumoral (TNF)-a. Essas modificações são mais evidentes após provas de maratona $a^{1,7,9}$ e testes prolongados em esteira ${ }^{1,14}$.

Os estudos que se propuseram a avaliar as modulações do sistema imunológico e incidência dos episódios de infecções decorrentes do treinamento e competições em esportes coletivos, principalmente ao longo dos períodos de preparação e competições ${ }^{5,16-24}$, são mais exíguos quando comparados aos esportes individuais e caracteristicamente de endurance $e^{1,5,6,8,9,11,13,14}$.

Nesse sentido, este trabalho está centrado em revisar: i) as interações entre o sistema imunológico e eixo neuroendócrino frente ao estresse do exercício e treinamento; ii) as conceituações, causas e quadro clínico (especificamente com relação as modulações nos parâmetros imunológicos) frente ao excesso de treinamento; iii) as modulações nos parâmetros imunológicos ao longo do treinamento e competições, com enfoque especial aos esportes coletivos, considerando a sua natureza intermitente; bem como iv) comparar às modulações imunológicas decorrentes de esportes individuais e caracteristicamente de endurance. Para tanto, foi realizada uma revisão de artigos científicos nacionais e internacionais, no período de dezembro de 2013 a dezembro de 2014, no portal científico da Capes e nas bases de dados SciELO, Science Direct, Highwiree PubMed, utilizando a combinação das seguintes palavras-chave: sistema imunológico, infecções, treinamento, esportes coletivos e excesso de treinamento. Foram utilizados como critérios de inclusão, estudos: i) originais/revisão; ii) que se utilizaram exclusivamente de atletas adolescentes ou adultos, não havendo restrição de gênero; bem como iii) que se dedicaram a avaliar qualquer tipo de parâmetro imunológico, associado ou não a parâmetros endócrinos e estratégias nutricionais relacionadas. Foi hipotetizado que, as modulações nos parâmetros imunológicos em atletas de esportes coletivos, observadas ao longo do treinamento e competições, apresentariam semelhanças as reconhecidas adaptações em atletas individuais e caracteristicamente de endurance.

\section{Exercício e respostas imunológicas: interações entre o sistema imunológico e eixo neuro-endócrino}

É reconhecido que tanto o estresse psicossocial ou psicológico e o estresse advindo do exercício, apresentam potencial efeito estimulador sobre o hipotálamo. Tal estimulação induz o hipotálamo (centro regulador) a sintetizar e liberar o hormônio liberador de corticotrofina (CRH). O CRH atua diretamente na hipófise, também denominada de glândula pituitária (centro retransmissor), que por sua vez, é estimulada a sintetizar e liberar a corticotrofina ou hormônio adreno-corticotrófico (ACTH). Finalmente o ACTH, liberado na circulação geral, induz as glândulas suprarrenais a iniciarem a síntese e liberação dos chamados hormônios do estresse, denominados de catecolaminas (adrenalina e noradrenalina), liberadas pela medula das adrenais; bem como do cortisol, liberado pelo córtex das adrenais. O eixo descrito anteriormente é denominado de eixo-hipotalâmico-pituitário-adrenal (HPA) ${ }^{25-28}$. Adicionalmente, as glândulas suprarrenais são diretamente estimuladas pelo sistema nervoso autônomo, por intermédio de vias simpáticas, induzindo estas a sintetizar e liberar as catecolaminas ${ }^{26-28}$ (Figura 1).

De fato, é reconhecido que, tanto o cortisol quanto as catecolaminas, apresentam ação direta sobre o sistema imunológico e consequente modulação desse sistema ${ }^{1,9,25,26}$ (Figura 1), sendo tal interação denominada de neuroendócrino-imunomodulação ${ }^{26}$.

Em adição, as citocinas pró-inflamatórias como IL-1 $\beta$, IL-6 e TNF-a têm sido correlacionadas com ativação do eixo HPA e inibição do eixo hipotalâmico-pituitário-gonadal $(\mathrm{HPG})^{25}$, demonstrando íntima relação destas citocinas com o eixo neuroendócrino e consequente modulação imunológica.

Vários estudos com modelos animais e humanos demonstraram aumentos agudos na contagem leucocitária durante e após exercícios em intensidades submáximas (aproximadamente $60 \% \mathrm{VO}_{2 \text { máx. }}$ ) até máximas, caracterizando os quadros denominados leucocitose, linfocitose, neutrofilia ou neutrocitose e monocitose, definidos como o aumento da contagem absoluta dos leucócitos, linfócitos, neutrófilos e monócitos circulantes, respectivamente ${ }^{1,11,29-35}$.

Modulações hemodinâmicas agudas, provocadas pela ativação simpática e imediata liberação das catecolaminas durante o exercício são tidas como fator primário para a leucocitose, promovendo a desmarginação dos leucócitos aderidos ao pool marginal e recrutamento celular dos locais de armazenamento e síntese celular para o sangue por ação mecânica' (Figura 2).

Antagonicamente, após exercícios realizados em intensidades máximas, ou mesmo submáximas, porém de duração prolongada (acima de 120 min), o aumento significante do cortisol promove inibição da mitogênese e/ou aceleração da apoptose linfocitária, provocando redução da contagem dos linfócitos circulantes abaixo dos valores basais, quadro este, denominado de linfopenia' (Figura 2).

Adicionalmente, o cortisol e a IL-6 apresentam efeitos posteriores sobre a mobilização dos neutrófilos da medula óssea para o sangue, exercendo uma resposta secundária, e adicionalmente, aumentando 
a contagem além dos padrões apresentados imediatamente ao final das sessões ${ }^{1}$ (Figura 2).

O efeito imunossupressor do exercício e aumentos nos episódios de ITRS em atletas é atribuído a um período denominado de "Janela Aberta", definido como um período transitório 1,6-8,11,36, onde o organismo se encontra mais susceptível as ITRS, podendo ter relação com as diminuições observadas nas contagens linfocitárias 1,6,11,36 (Figura 2).

Nessa linha de pensamento, em uma clássica e extensa revisão, Pedersen e Hoffman-Goetz ${ }^{1}$, relatam as modulações nos parâmetros imunológicos decorrentes do exercício e do treinamento realizado por atletas, prioritariamente de esportes individuais e caracteristicamente de endurance. As catecolaminas exercem efeitos agudos ou imediatos sobre a mobilização dos leucócitos (neutrófilos, monócitos e linfócitos) para o sangue durante as sessões de exercícios; enquanto o cortisol promove efeitos tardios sobre a mobilização dos neutrófilos para a circulação geral concomitantemente à inibição na mitogênese e funcionalidade dos linfócitos, consequentemente podendo promover a "Janela Aberta" e concomitantemente aumentando a incidência aos episódios de ITRS (Tabela 1).

Ressalta-se que essa aumentada incidência aos episódios de ITRS e que pode ser decorrente primariamente das excessivas cargas de treinamento e competições associadas a insuficientes períodos de

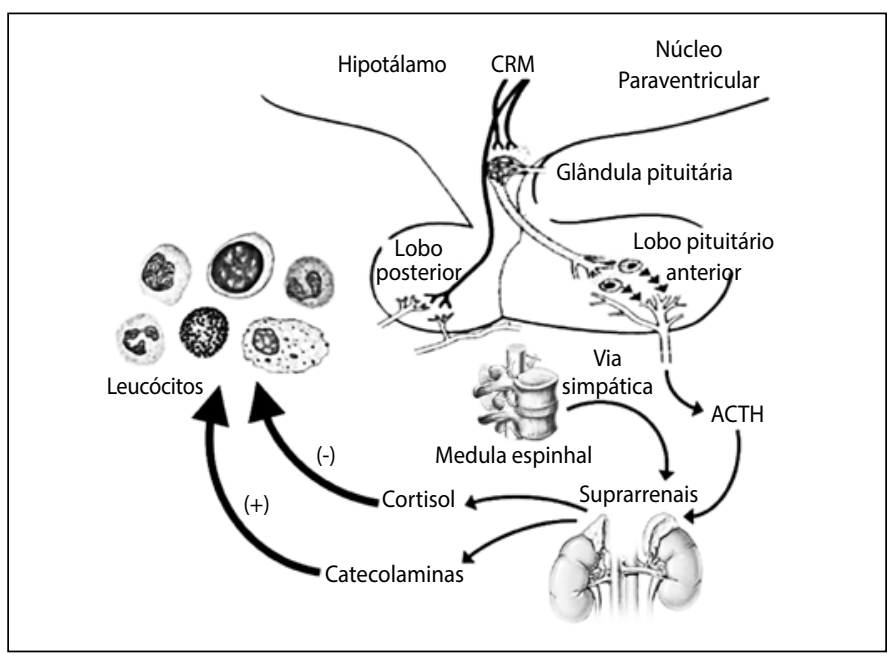

Figura 1. Anatomia e fisiologia do eixo hipotalâmico-pituitário-adrenal e consequente ação sobre o sistema imunológico; (+) estimulação, (-) inibição; CRH: hormônio liberador de corticotrofina, ACTH: hormônio adreno-corticotrófico.

Modificado de Turnbull e Rivier'5.

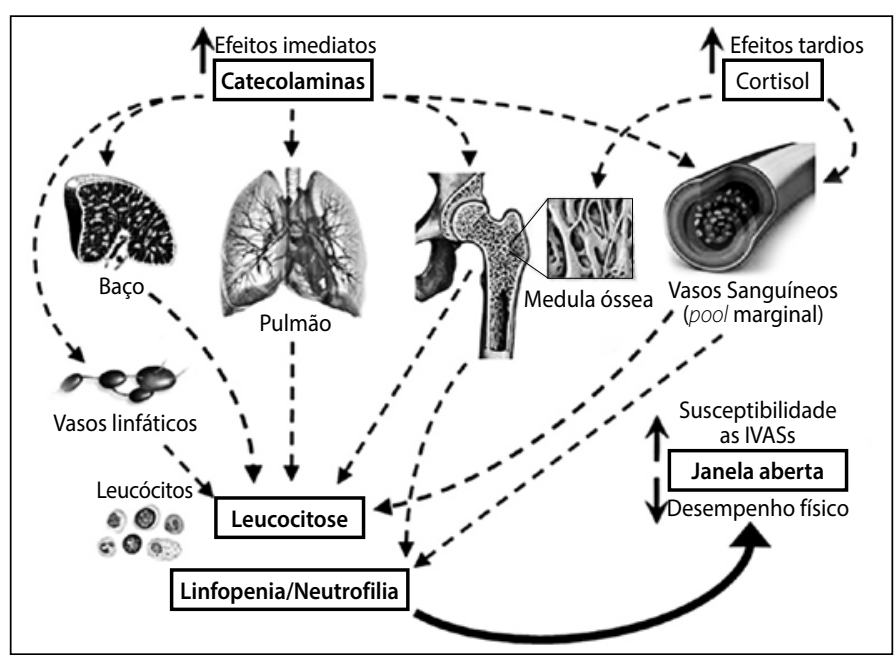

Figura 2. Possíveis locais de mobilização dos leucócitos para o sangue, em decorrência dos efeitos imediatos exercidos pelas catecolaminas, bem como efeitos tardios exercidos pelo cortisol. recuperação' ${ }^{1}$, enaltece a necessidade de uma adequada periodização do treinamento ao longo de todo o ciclo anual.

Nessa linha de pensamento, também tem sido dada atenção as estratégias com relação a manipulação das cargas de treinamento anteriormente as competições, sendo tal estratégia, comumente denominada de polimento ou taper ${ }^{37-39}$. Nessa referida estratégia, o volume de trabalho diminui de forma acentuada, porém a intensidade mantém-se em níveis elevados nas sessões que antecedem as competições, objetivando acentuar as adaptações ao treinamento sob as perspectivas: metabólicas, cardiorrespiratórias, bioquímicas, hormonais, neuromusculares, estado de humor, percepção do esforço, qualidade do sono e imunológicas; visando aperfeiçoar o desempenho esportivo ${ }^{37-39}$

\section{Excesso de treinamento: conceituação, possíveis causas e quadro clínico}

A síndrome do excesso de treinamento (overtraining) é definida como um complexo conjunto de desordens neuroendócrinas, que ocorrem no eixo HPA e HPG, caracterizada por persistente fadiga, distúrbios do sono, alterações no estado de humor, supressão da atividade reprodutiva, diminuição do desempenho, incapacidade de manter as cargas de treinamento e competições, assim como aumento na incidência de infecções, especialmente as ITRS 3,13,40-47.

Quanto a duração do quadro clínico, é importante destacar que a síndrome do overtraining denota o chamado excesso de treinamento com queda persistente do desempenho em longo prazo (perdurando mais de 3 semanas), enquanto que o overreaching denota um excesso de treinamento com queda no desempenho a curto prazo (perdurando menos de 3 semanas) e proporcionando ao atleta a super compensação em momentos adequados ${ }^{41,42,44}$, sendo caracterizado como overreaching funcional ${ }^{44}$.

O quadro clínico do overreaching pode incidir após vários dias de treinamento intenso, estando associado à fadiga muscular ou periférica. A reversão do overreaching ocorre após dias de afastamento dos treinamentos ou diminuição das cargas de treinamento ${ }^{41,42}$, podendo ocorrer até mesmo uma melhora no desempenho ${ }^{41,44}$, neste caso, o overreaching funcional ${ }^{44}$, em decorrência de adaptações orgânicas ao estresse do treinamento.

Tabela 1. Respostas na contagem e funcionalidade dos leucócitos circulantes, durante e após sessões de treinamentos e competições realizadas por atletas.

\begin{tabular}{c|c|c}
\hline Parâmetros imunológicos & $\begin{array}{c}\text { Efeitos } \\
\text { imediatos } \\
\text { (Catecolaminas) }\end{array}$ & $\begin{array}{c}\text { Efeitos tardios } \\
\text { (Cortisol) }\end{array}$ \\
\hline Contagem dos Leucócitos & $\uparrow$ & $\uparrow \uparrow$ \\
\hline Contagem dos Neutrófilos Totais & $\uparrow$ & $\uparrow \uparrow$ \\
\hline Contagem dos Monócitos & $\longleftrightarrow$ & $\uparrow$ \\
\hline Contagem dos Linfócitos Totais & $\uparrow$ & $\downarrow$ \\
\hline Contagem dos Linfócitos T (CD4+) & $\uparrow$ & $\downarrow$ \\
\hline Contagem dos Linfócitos T (CD8 ${ }^{+}$) & $\uparrow$ & $\downarrow$ \\
\hline Contagem dos Linfócitos B (CD19+) & $\uparrow$ & $\downarrow$ \\
\hline Contagem dos Linfócitos NK (CD16 $56^{+}$) & $\uparrow$ & $\downarrow$ \\
\hline Apoptose dos Linfócitos & $\uparrow$ & $\downarrow$ \\
\hline Proliferação dos Linfócitos & $\downarrow$ & $\downarrow$ \\
\hline Concentração de Ig-A salivar & $\downarrow$ & $\downarrow$ \\
\hline Citotoxicidade dos Linfócitos NK & $\uparrow$ & $\uparrow$ \\
\hline Concentração Sérica de TNF-a & $\uparrow$ & $\uparrow$ \\
\hline Concentração Sérica de IL-1 $\beta$ & $\uparrow$ & $\uparrow$ \\
\hline Concentração Sérica de IL-6 & $\uparrow \uparrow$ & $\uparrow$ \\
\hline
\end{tabular}

Modificado de Pedersen e Hoffman-Goetz1. ( $\uparrow$ : aumento; $(\downarrow)$ : diminuição; $(\uparrow \uparrow)$ : aumento pronunciado; $(\longleftrightarrow$ manutenção. 
Quanto ao overtraining, para que ocorra a sua reversão, parece ser essencial um período de semanas a meses de afastamento dos treinamentos e competições ${ }^{41,42}$, sendo necessário impreterivelmente o repouso total do atleta por um período médio não inferior a cinco semanas, podendo chegar a 12 semanas $^{42}$.

No entanto, é importante considerar que os sintomas do overreaching e overtraining podem se confundir, existindo dessa forma, uma linha muito tênue entre melhora do desempenho e propensão para o overtraining ${ }^{41,44}$. Apesar do grande número de pesquisas relacionadas ao overtraining, ainda não existe consenso entre os pesquisadores quanto à utilização de um marcador exclusivo e eficaz ${ }^{7,41,43-46}$.

Tais marcadores se configuram como: i) fisiológicos: frequência cardíaca de repouso, consumo máximo de oxigênio $\left(\mathrm{VO}_{2 \text { máx }}\right)$, concentrações de lactato em repouso e no exercício; ii) hormonais e bioquímicos: excreção urinária de noradrenalina, concentração de testosterona e cortisol, razão testosterona/cortisol, concentrações de creatina quinase, mioglobina, fragmento de cadeia pesada de miosina, dentre outros; iii) psicológicos: perfil do estado de humor e percepção subjetiva de esforço e cansaço; iv) nutricionais: perfil alimentar (hipovitaminoses e hipervitaminoses); assim como v) imunológicos 3,4,7,40-46,48,49.

Considerando as respostas tanto agudas como crônicas inerentes ao sistema imunológico em decorrência do treinamento e competições ${ }^{1,41}$, têm sido propostos em importantes revisões, alguns potenciais marcadores imunológicos para o diagnóstico clínico e prevenção da síndrome do overtraining como apoptose e proliferação linfocitária, concentração de Ig-A salivar, bem como citotoxicidade das células NK. Em adição, outros marcadores também têm sido sugeridos, como contagem dos leucócitos, razão neutrófilos totais/linfócitos totais, razão $\mathrm{CD} 4^{+} / \mathrm{CD} 8^{+}$, razão linfócitos T-helper (Th)1/Th2 e concentrações séricas das citocinas pró-inflamatórias como IL-2, IL-6 e TNF-a $a^{3,7,41}$.

Dessa forma, o entendimento das modulações nas variáveis imunológicas conjuntamente as cargas de treinamento e competições ao logo da temporada, a adoção de estratégias práticas quanto ao gerenciamento do estado imunológico ${ }^{4,48}$ e questões nutricionais relacionadas ${ }^{1,6}$, podem fornecer subsídios para a melhora do desempenho e prevenção da síndrome do overtraining.

\section{Treinamento e respostas imunológicas: uma visão geral}

Baseado nas evidências de que o estresse do exercício pode modular os parâmetros imunológicos, a teoria da "Curva em J" tem sido extensivamente considerada na imunologia do exercício. De acordo com essa hipótese, o exercício com cargas moderadas concomitantemente a alterações positivas no sistema imunológico, protegeria os indivíduos das infecções; ao passo que o exercício realizado com cargas excessivas, concomitantemente a alterações negativas nesse mesmo sistema, aumentaria o número de episódios de infecções em um dado período, acima dos índices apresentados em indivíduos sedentários ${ }^{50}$, caracterizando um estado anérgico (diminuição da capacidade de defesa) $4,36,50$ (Figura 3A).

Porém, nos atletas avaliados para formulação da referida "Curva em J"50 (Figura 3A), não foi distinguido a diferença entre "carga alta" e "carga de elite". Considerando a referida distinção, quando atletas de elite são inclusos no modelo, a relação entre carga de exercício e risco de infecções, apresenta uma "Curva em S", demonstrando que os atletas de elite apresentariam menor possibilidade de ocorrência de episódios de infecções, quando comparados às altas cargas de treinamento, realizadas por atletas que não são considerados como de elite (Figura 3B) ${ }^{51}$.

Durante uma sessão de exercício em intensidade e volume moderado, muitas alterações positivas, tanto nas contagens bem como nos parâmetros funcionais dos leucócitos, ocorrem no sistema imunológi$\mathrm{co}^{1,4,8-11}$. Embora os parâmetros imunológicos, sob tais circunstâncias de esforço, retornem aos padrões normais muito rapidamente, cada sessão representa um estímulo agudo que parece reduzir o risco de ITRS cronicamente ${ }^{36}$ (Figura 4).

No entanto, as cargas comumente elevadas das sessões de treinamento realizadas por atletas, podem provocar um efeito imunossupressor, em decorrência do estresse fisiológico que modula negativamente a resposta imunológica, podendo induzir a instalação da "Janela Aberta"e aumentos nos episódios de ITRS 1,4,6,8,11,36,48. Esse período imunossupressor transitório pode levar aproximadamente 3-24 horas após uma sessão de treinamento prolongado (>1,5 horas) de moderada a alta intensidade (55-75\% VO $\mathrm{VO}_{2 \text { má. }}{ }^{1,5,6,12,13}$; chegando até 1-2 semanas após eventos extremos, como uma maratona. Antagonicamente, sessões realizadas em intensidades leves a moderadas com duração não superior a 30-45 minutos não parecem induzir o estado imuno-supressor 1,4,9 (Figura 4).

Modulações no sistema imunológico como, aumentos nas contagens dos neutrófilos e diminuição nos linfócitos circulantes ${ }^{1,14}$; redução da proliferação dos linfócitos e citotoxicidade das células NK ${ }^{1,13,14}$; aumento da apoptose dos linfócitos ${ }^{1,13}$; redução da imunidade da mucosa, em decorrência de diminuições nas concentrações séricas de anticorpos específicos, principalmente a lg- $A^{1,3,7,15}$ e aumentos nas concentrações séricas das citocinas pró-inflamatórias, principalmente IL-1 $\beta$, IL-6 e TNF-a após provas de maratona ${ }^{1,7,9}$, assim como testes prolongados em

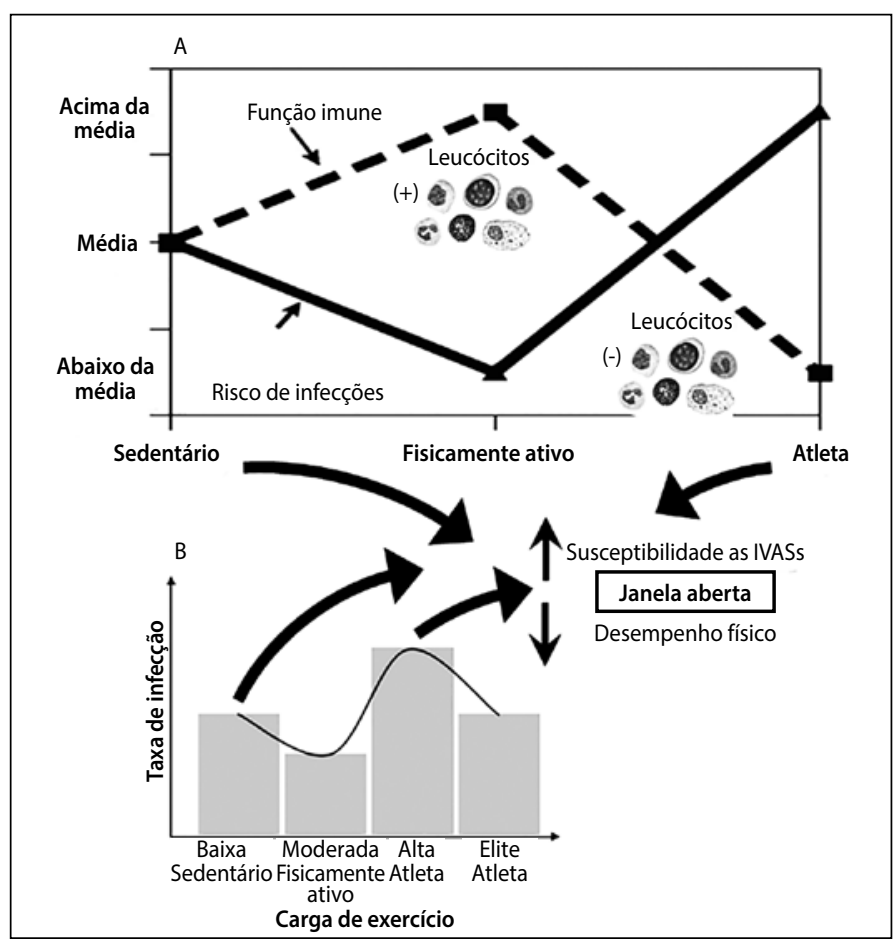

Figura 3. Risco de infecções e função imunológica relacionada ao nível de treinabilidade; (+) estimulação, (-) inibição; (A): modificado de Nieman ${ }^{36}$; (B): modificado de Malm¹.

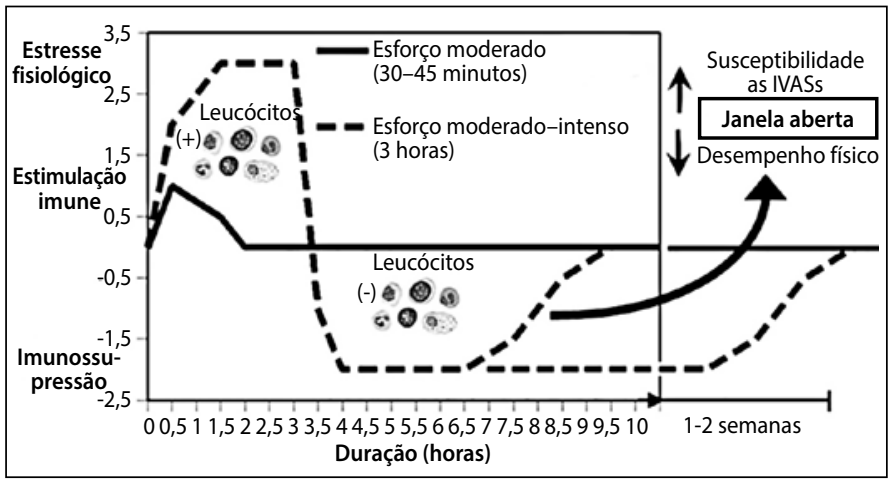

Figura 4. Estado imunológico decorrente do esforço em intensidades evolumes moderados por indivíduos fisicamente ativos, comparado ao treinamento e competições realizadas por atletas de alto nível; (+) estimulação, (-) inibição. Modificado de Nieman e Bishop ${ }^{12}$. 
esteira ${ }^{1,14}$, tem sido correlacionados com aumentos nos episódios de ITRS, em decorrência de excessivas cargas de treinamento e competições associadas a insuficientes períodos de recuperação (Tabela 1).

No que se refere aos anticorpos da mucosa, reconhecidamente existem diferentes classes dessas proteínas como lg- $A$, lg-G e lg-M13,3,52. Tais classes de anticorpos da mucosa são consideradas pelos imunologistas como a primeira linha de defesa contra as ITRS 1,3,7.

Diminuição da concentração salivar de lg-A foram demonstradas após sessões de treinamento ou competições realizadas por atletas 3,7,15. Contrariamente, o exercício submáximo parece não apresentar potencial para alterar as concentrações de lg-A salivar 1,3. Nesse sentido, as concentrações de lg-A salivar adicionalmente às outras variáveis funcionais, constituem-se importantes ferramentas para a avaliação do quadro imunológico.

\section{Treinamento, competições e respostas imunológicas: modulações nos parâmetros imunológicos em esportes coletivos}

Como já evidenciado, aumentos nos episódios de ITRS parecem apresentar relação tanto com alterações nas contagens ${ }^{1,14}$, bem como na funcionalidade dos leucócitos circulantes ${ }^{1,7,13-15}$ assim como nas concentrações séricas das citocinas pró-inflamatórias, principalmente IL-1 $\beta$, IL-6 e TNF- $a$ após provas de maratona ${ }^{1,7,9,53}$, e testes prolongados em esteira ${ }^{1,14,53}$ (Tabela 1). Com relação aos esportes coletivos como futebol americano ${ }^{17}$, futebol ${ }^{18}$, basquetebol ${ }^{16,19,22,23}$ e voleibol $^{20,21,24}$, as pesquisas são notoriamente mais exíguas (Tabela 2).

Benoni et al. ${ }^{16}$ avaliaram jogadores de basquete quanto às contagens e parâmetros funcionais dos leucócitos evidenciando: aumento

Tabela 2. Respostas na contagem e funcionalidade dos leucócitos circulantes ao longo dos períodos de preparação e competições realizadas por atletas.

\begin{tabular}{|c|c|}
\hline Parâmetros imunológicos & $\begin{array}{l}\text { Efeito somatório das cargas de } \\
\text { treinamento e competições }\end{array}$ \\
\hline Contagem dos Leucócitos & $\uparrow^{(3)} \leftrightarrow(4)$ \\
\hline Contagem dos Neutrófilos Totais & $\uparrow^{(5)} \leftrightarrow(2)$ \\
\hline Contagem dos Monócitos & $\downarrow^{(1)} \leftrightarrow{ }^{(1)} \uparrow^{(2)}$ \\
\hline Contagem dos Linfócitos Totais & $\downarrow^{(2)} \leftrightarrow{ }^{(4)} \uparrow^{(1)}$ \\
\hline Contagem dos Linfócitos $\mathrm{T}\left(\mathrm{CD}^{+}{ }^{+}\right)$ & $\downarrow^{(1)}$ \\
\hline Contagem dos Linfócitos T (CD8 $\left.{ }^{+}\right)$ & $\leftrightarrow \leftrightarrow^{(1)}$ \\
\hline $\begin{array}{l}\text { Contagem dos Linfócitos } \\
\text { NK }\left(C D 16^{+} 56^{+}\right)\end{array}$ & $\leftrightarrow \leftrightarrow^{(1)}$ \\
\hline Proliferação dos Linfócitos & $\downarrow^{(1)}$ \\
\hline Citotoxicidade dos Linfócitos NK & $\downarrow^{(1)}$ \\
\hline Fagocitose dos Neutrófilos & $\downarrow^{(1)}$ \\
\hline Citotoxicidade dos Neutrófilos & $\uparrow^{(1)}$ \\
\hline Adesão dos Neutrófilos & $\downarrow^{(2)}$ \\
\hline Concentração Sérica de TNF-a & $\uparrow^{(1)} \leftrightarrow^{(3)}$ \\
\hline Concentração Sérica de IL-6 & $\uparrow^{(1)} \leftrightarrow^{(3)}$ \\
\hline Concentração Sérica de IFN-y & $\leftrightarrow \leftrightarrow^{(1)}$ \\
\hline Concentração Sérica de IL-2 & $\leftrightarrow \leftrightarrow^{(1)}$ \\
\hline Concentração Sérica de IL-10 & $\downarrow^{(1)}$ \\
\hline Concentração Sérica de PCR & $\uparrow^{(1)}$ \\
\hline Concentração Sérica de Leptina & $\leftrightarrow(1)$ \\
\hline Concentração Sérica de Adiponectina & $\leftrightarrow \leftrightarrow^{(1)}$ \\
\hline Concentração Sérica de Resistina & $\leftrightarrow^{(1)}$ \\
\hline
\end{tabular}

( ): aumento; $(\downarrow)$ : diminuição; $(\leftrightarrow)$ : manutençăo; os números em expoentes denotam a quantidade de estudos encontrados/relacionados a cada parâmetro imunológico avaliado. nas contagens absolutas dos leucócitos, monócitos, neutrófilos totais, eosinófilos e linfócitos totais ao final da temporada; retornando aos valores iniciais três semanas após o final da temporada; aumento da atividade bactericida com concomitante diminuição da adesão dos neutrófilos ao final da temporada, similarmente retornando aos valores iniciais três semanas após o final da temporada (Tabela 2).

Quanto à contagem dos leucócitos, Rebelo et al. ${ }^{18}$ avaliaram jogadores de futebol e evidenciaram: aumento nas contagens absolutas dos leucócitos e neutrófilos totais ao final da temporada; porém manutenção nos eosinófilos e linfócitos totais ao longo da temporada; especificamente os monócitos e linfócitos T CD4+ apresentaram aumento no meio da temporada competitiva, retornando aos valores iniciais ao final da temporada (Tabela 2).

Bury et al. ${ }^{17}$ avaliaram jogadores de futebol americano quanto às contagens e parâmetros funcionais dos leucócitos evidenciando: manutenção nos leucócitos; aumento nos neutrófilos totais; diminuição nos linfócitos totais; diminuição nos linfócitos T CD4+; manutenção nos linfócitos T CD8 ${ }^{+}$bem como nas contagens das células NK ao final da temporada, retornando aos valores iniciais na temporada seguinte (2 meses após); diminuição na proliferação dos linfócitos T CD4 $4^{+}$e T $\mathrm{CD}^{+}$; diminuição da fagocitose e adesão dos neutrófilos ao final da temporada, similarmente retornando aos valores iniciais na temporada seguinte (2 meses após). Ademais, foram observados 22 episódios de ITRS nos atletas contra nove para o grupo controle sedentário, durante todo o ciclo anual de treinamento e competições, sugerindo relação com a diminuição dos indicadores funcionais (Tabela 2).

Suzui et al. ${ }^{20}$ observaram jogadores de voleibol quanto às contagens e parâmetros funcionais dos leucócitos evidenciando: manutenção nas contagens absolutas dos leucócitos, neutrófilos totais, monócitos, basófilos, eosinófilos e linfócitos totais; assim como nas concentrações séricas das citocinas pró-inflamatórias interferon (IFN)-y, IL-6 e TNF-a; porém diminuição na citotoxicidade das células NK, após um mês de aumento na carga de treinamento e competições na pré-temporada (Tabela 2).

Nosso grupo de pesquisa também tem se dedicado a procurar entender as modulações imunológicas ao longo de períodos de treinamento e competições em esportes coletivos como basquetebol ${ }^{22,23}$ e voleibol $^{21,24}$, a fim de contribuir com o gerenciamento da saúde dos atletas.

Nesse sentido, Brunelli et al. ${ }^{22}$ avaliaram jogadores de basquete quanto às contagens e parâmetros funcionais dos leucócitos e observaram: manutenção nas contagens absolutas dos leucócitos, neutrófilos totais e linfócitos totais; diminuição nas contagens absolutas dos monócitos; manutenção nas concentrações séricas das citocinas pró-inflamatórias IL-6 e TNF-a ao final do período preparatório; bem como maior incidência dos episódios de ITRS ao longo das duas semanas iniciais do referido período (totalizando os primeiros $25 \%$ do período preparatório) (Tabela 2).

Ainda, Brunelli et al. ${ }^{23}$ avaliaram jogadores de basquete quanto às contagens e parâmetros funcionais dos leucócitos e observaram: manutenção nas contagens absolutas dos leucócitos e linfócitos totais; aumento nas contagens absolutas dos monócitos e neutrófilos totais; aumento nas concentrações séricas das citocinas pró-inflamatórias IL-6, TNF-a e proteína C-reativa (PCR); diminuição nas concentrações séricas da citocina anti-inflamatória IL-10 ao final do período competitivo; bem como maior incidência dos episódios de ITRS durante o referido período e apresentando correlação com a monotonia (índice de variabilidade do treinamento) (Tabela 2).

Dias et al. ${ }^{21}$ avaliaram jogadores de voleibol quanto as contagens e parâmetros funcionais dos leucócitos e encontraram: aumento nas contagens absolutas dos leucócitos e monócitos no meio da temporada competitiva com manutenção dos mesmos ao final da temporada; 
aumento dos neutrófilos totais e diminuição dos linfócitos totais ao final da temporada; manutenção nas concentrações séricas das citocinas IL-2, IL-6 e TNF-a ao longo da temporada. Ademais, foram observados aumento dos episódios de ITRS no meio da temporada competitiva com manutenção dos mesmos ao final da temporada, sendo que os episódios de ITRS apresentaram correlação positiva com os indicadores da carga de treinamento (Tabela 2). Ademais, Yamada et al..$^{24}$ também avaliaram jogadores de voleibol quanto aos parâmetros funcionais dos leucócitos e encontraram: manutenção nas concentrações séricas das citocinas pró-inflamatórias leptina e resistina bem como da citocina anti-inflamatória adiponectina (Tabela 2).

Além da reconhecida relação com a defesa do organismo e consequente susceptibilidade às infecções, o sistema imunológico recentemente tem sido cogitado como participante das adaptações musculoesqueléticas induzidas pelo treinamento e competições. A própria síntese de determinadas citocinas pelo tecido muscular 1,53-57, sugere participação das mesmas nesse processo.

Nesse sentido, concentrações séricas elevadas das citocinas pró-inflamatórias como IL-1 $\beta$, IL-6 e TNF-a, têm sido correlacionados com inibição do eixo hormônio do crescimento - fator de crescimento insulínico (GH-IGF-I) nos estágios iniciais do treinamento ${ }^{58}$. Adicionalmente, foi observado aumento da proteólise muscular em ratos tratados com TNF-a ${ }^{59}$; assim como em culturas de mioblastos de humanos, inibição do aumento da síntese proteica pelos fatores de crescimento, após tratamento com TNF-a ${ }^{60}$

Com relação às contagens celulares, o quadro clínico da leucocitose, que comumente pode estar associado a algumas doenças ${ }^{52}$, não necessariamente se aplica a atletas, já que o efeito somatório das cargas de treinamento e competições pode ser o único responsável pelo maior limiar de contagem dos leucócitos circulantes, podendo esse quadro ser considerado para a referida população, como clinicamente dentro da normalidade, havendo a necessidade de uma interpretação clínica diferenciada entre indivíduos sedentários e atletas ${ }^{49}$

Apesar da contagem dos monócitos e linfócitos totais bem como linfócitos T CD4 ${ }^{+}$e T CD8 ${ }^{+}$apresentarem respostas mais diferenciadas (diminuição, manutenção ou aumento), os neutrófilos parecem apresentar um padrão mais similar de resposta (aumento) ao longo do treinamento e competições ${ }^{16-18,21,23}$ (Tabela 2).

É possível que o aumento na contagem dos neutrófilos nos estudos revisados $16-18,21,23$ (Tabela 2), seja decorrente do maior grau de dano tecidual, necessitando das referidas células para a promoção dos processos de regeneração muscular, associada a uma capacidade da medula óssea em prontamente disponibilizar células para o sangue. Ademais, tal modulação celular pode estar mais relacionada com os efeitos tardios exercidos pelo cortisol e IL-6!'.

Ainda, a diminuição na contagem dos linfócitos totais bem como nos linfócitos TCD4+, diminuição na proliferação dos linfócitos T CD4+ eT $\mathrm{CD}^{+}$, bem como aumento da incidência de ITRS ${ }^{17,21}$ (Tabela 2), também pode estar relacionada com os efeitos tardios e somatórios exercidos pelo cortisol ${ }^{1}$. No que diz respeito aos estudos onde foram observados aumento e/ou manutenção nas contagens linfocitárias ao final da temporada ou período de treinamento ${ }^{16,18,20,23}$ (Tabela 2), é permissível hipotetizar que as cargas de treinamento e competições delineadas, não apresentaram potencial efeito somatório para induzir linfopenia.

Realizando uma comparação dos estudos revisados, no que diz respeito às modulações do sistema imunológico decorrentes de esportes coletivos ao longo do treinamento e/ou competições ${ }^{16-24}$ (Tabela 2), com as modulações propostas por Pedersen e Hoffman-Goetz', observadas ao longo do treinamento e competições, porém prioritariamente em atletas de esportes individuais e caracteristicamente de endurance (Tabela 1); é observado similaridade no comportamento de ao menos uma das variáveis imunológicas em cada um dos referidos estudos revisados, demonstrando aumento na contagem dos neutrófilos ${ }^{16-18,21,23}$ e/ou diminuição na contagem dos linfócitos ${ }^{17,21}$; bem como na funcionalidade de alguma variável linfocitária17,20 (Tabela 2), confirmando a hipótese inicial do presente estudo.

No que diz respeito à funcionalidade dos leucócitos, os referidos estudos relativos aos esportes coletivos ${ }^{16-24}$ se propuseram a investigar a proliferação dos linfócitos T $\mathrm{CD}^{+}{ }^{+}$e $T \mathrm{CD}^{+17}$; a funcionalidade das células NK ${ }^{20}$; a atividade bactericida dos neutrófilos ${ }^{16}$; a fagocitose dos neutrófilos ${ }^{17}$; a adesão dos neutrófilos ${ }^{16,17}$; a incidência de ITRS 19,21-23; bem como as concentrações séricas das citocinas IFN-y, IL-2, IL-6, IL-10, TNF-a, PCR, leptina, adiponectina e resistina20-24 (Tabela 2); não sendo encontrados até o presente momento, estudos que se propuseram a avaliar as modulações na imunidade da mucosa ao longo de uma temporada, abrindo novas perspectivas de investigação.

Nos referidos estudos revisados ${ }^{16-24}$, foi observado que, enquanto a funcionalidade dos linfócitos parece apresentar um padrão mais similar de resposta (diminuição), os neutrófilos parecem apresentar respostas mais diferenciadas, dependendo da variável avaliada (diminuição ou aumento) ao longo do treinamento e competições ${ }^{16-18,20-22}$ (Tabela 2). É possível que a diminuição na capacidade funcional dos linfócitos possa ser regulada pela melhora nas contagens bem como em variáveis funcionais dos neutrófilos e macrófagos, contrabalanceando a redução na atividade linfoide. Entretanto, em razão da escassez de estudos que se dispuseram a avaliar a funcionalidade dos leucócitos em esportes coletivos, durante os períodos de treinamento e competições ${ }^{16-18,20-24}$ (Tabela 2), as conclusões sobre esse tópico, ficam limitadas.

Conforme apresentado anteriormente, realizando uma comparação dos estudos revisados, no que diz respeito às modulações do sistema imunológico decorrentes de esportes coletivos ao longo do treinamento e competições ${ }^{16-24}$ (Tabela 2), com as modulações propostas por Pedersen e Hoffman-Goetz' , observadas similarmente ao longo do treinamento e competições, porém prioritariamente em atletas de esportes individuais e caracteristicamente de endurance (Tabela 1); é observado similaridade no comportamento quanto a funcionalidade das variáveis linfocitárias avaliadas ${ }^{17,20,23}$ (Tabela 2), adicionalmente confirmando a hipótese inicial do presente estudo

Ademais, dos poucos estudos que se propuseram a investigar as modulações imunológicas em esportes coletivos ao longo da temporada ${ }^{16,-24}$, apenas quatro se propuseram a relacionar tais modulações com a incidência de ITRS 17,21-23 (Tabela 2). Outro ponto que chama a atenção, é o fato de apenas um estudo, ter procurado entender tais modulações sob a perspectiva das contagens absolutas e relativas dos leucócitos ${ }^{18}$, com a maioria dos estudos enfatizando somente as contagens absolutas ${ }^{16,17,20-23}$ sendo que, apenas dois estudos se preocuparam em utilizar um grupo controle composto por uma população saudável não atleta ${ }^{17,20}$ (Tabela 2), adicionalmente abrindo perspectivas para investigações futuras.

\section{CONSIDERAÇÕES FINAIS}

As modulações nas contagens dos leucócitos observadas ao longo da temporada, modulações estas que são decorrentes do efeito somatório das cargas de treinamento e competições, quando analisadas especificamente quanto aos neutrófilos e monócitos, possivelmente se relacionam com os processos de reparo tecidual e incidência de ITRS. Entretanto, as modulações relacionadas aos linfócitos, parecem estar mais relacionadas diretamente com a incidência das ITRS.

Entende-se como de suma importância, o delineamento de estudos com a proposta de entender tais parâmetros quanto as contagens e funcionalidade dos leucócitos, procurando inferir correlações com a 
incidência das ITRS, sazonalidade, indicadores de desempenho e controle do treinamento ao longo de todo o ciclo anual com a adoção de um grupo controle.

Ademais, o entendimento integrado de todos os marcadores propostos, parece ser um caminho mais promissor para o diagnóstico clínico do estado imunológico do atleta e prevenção da síndrome do overtraining do que necessariamente a busca por um marcador exclusivo de excesso de treinamento.

\section{AGRADECIMENTOS}

Os autores agradecem à Coordenação de Aperfeiçoamento de Pessoal de Nível Superior (CAPES) pelo apoio financeiro por meio do programa CAPES/PROSUP.

Todos os autores declararam não haver qualquer potencial conflito de interesses referente a este artigo.

CONTRIBUIÇÕES DOS AUTORES: Cada autor contribuiu individual e significativamente para o desenvolvimento do manuscrito. RD (0000-0001-6625-5805)*, RJB (00000003-4828-5212)*, FC (0000-0002-7922-129X)*, KK (0000-0002-5267-1864)* e CRC (0000-0002-7795-6575)* foram os principais contribuintes da redação do manuscrito, revisão de literatura, discussão dos estudos relacionados e apontamentos finais associados. RD e FC contribuíram com a criação/estruturação de todas as figuras do estudo. NFC (0000-0003-4820-2034)*, RV (0000-0001-8626-0476)*, CRL (0000-0003-4278-4969)*, JP (0000-0003-0399-8817)* e CAS (0000-0001-8855-9703)* realizaram a revisão do manuscrito e contribuíram com o conceito intelectual do estudo, discussão dos estudos relacionados e apontamentos associados. RD, RJB, RV, CRL, JP, CAS e CRC, participaram da aprovação da versão final do trabalho. *ORCID (Open Researcher and Contributor ID).

\section{REFERÊNCIAS}

1. Pedersen BK, Hoffman-Goetz L. Exercise and the immune system: regulation, integration, and adaptation. Physiol Rev. 2000;80(3):1055-81.

2. Gleeson M, Nieman DC, Pedersen BK. Exercise, nutrition and immune function.J Sports Sci. 2004;22(1):115-25.

3. Gleeson M, Pyne DB. Exercise effects on mucosal immunity. Immunol Cell Biol. 2000;78:536-44.

4. Gleeson M, Walsh NP. British Association of Sport and Exercise Sciences. The BASES expert statement on exercise, immunity, and infection. J Sports Sci. 2012;30(3):321-4.

5. Solivellas BM, Martín TC. Polypodium leucotomos Extract use to prevent and reduce the risk of infectious diseases in high performance athletes. Infect Drug Resist. 2012;5:149-53.

6. Gunzer W, Konrad M, Pail E. Exercise-induced immunodepression in endurance athletes and nutritional intervention with carbohydrate, protein and fat-what is possible, what is not? Nutrients. 2012;4(9):1187-212.

7. Papacosta $E$, Gleeson M. Effects of intensified training and taper on immune function. Rev Bras Educ Fís Esporte. 2013;27(1):159-76.

8. Couto M, Silva D, Delgado L, Moreira A. Exercise and airway injury in athletes. Acta Med Port. 2013;26(1):56-60.

9. Pedersen BK, Toft AD. Effects of exercise on lymphocytes and cytokines. Br J Sports Med. 2000;34(4):246-51.

10. Nieman DC, Henson DA, Austin MD, Brown VA. Immune response to a 30-minute walk. Med Sci Sports Exerc. 2005;37(1):57-62

11. Prestes J, Foschini D, Donatto FF. Physical exercises effect on the immune system. Rev Atenção Saúde. 2006; $4(7): 57-65$.

12. Nieman DC, Bishop NC. Nutritional strategies to counter stress to the immune system in athletes, with special reference to football. J Sports Sci. 2006;24(7):763-72.

13. Gleeson M. Immune function in sport and exercise. J Appl Physiol. 2007;103(2): 693-9.

14. Steensberg A, Toft AD, Bruunsgaard H, Sandmand M, Halkjaer-Krisrtensen J, Pedersen BK. Strenuous exercise decreases the percentage of type 1T cells in the circulation. J Appl Physiol. 2001;91(4):1708-12.

15. Steerenberg PA, van-Aspersen IA, van-Nieuw-Amerongen A, Biewenga A, Mol D, Medema GJ. Salivary levels of immunoglobulin A in triathletes. Eur J Oral Sci. 1997;105(4):305-9.

16. Benoni G, Bellavite P, Adami A, Chirumbolo S, Lippi G, Brocco G, et al. Changes in several neutrophil functions in basketball players before, during and after the sports season. Int J Sports Med. 1995;16(1):34-7.

17. Bury T, Marechal R, Mahieu P, Pirnay F. Immunological status of competitive football players during the training season. Int J Sports Med. 1998;19(5):364-8.

18. Rebelo AN, Candeias JR, Fraga MM, Duarte JA, Soares JM, Magalhães C, et al. The impact of soccer training on the immune system. J Sports Med Phys Fitness. 1998;38(3):258-61.

19. Anderson L, Triplett-McBride T, Foster C, Doberstein S, Brice G. Impact of training patterns on incidence of illness and injury during a women's collegiate basketball season. J Strength Cond Res. 2003;17(4):734-8.

20. Suzui M, Kawai T, Kimura H, Takeda K, Yagita H, Okumura K, et al. Natural killer cell lytic activity and CD56dim and CD56bright cell distributions during and after intensive training. J Appl Physiol. 2004;96(6):2167-73.

21. Dias R, Frollini AB, Brunelli DT, Yamada AK, Leite RD, Simöes RA, et al. Immune parameters, symptoms of upper respiratory tract infections, and training-load indicators in volleyball athletes. Int J Gen Med. 2011;4:837-44.

22. Brunelli DT, Borin JP, Rodrigues A, Bonganha V, Prestes J, Montagner PC, et al. Immune responses, upper respiratory illness symptoms, and load changes in young athletes during the preparatory period of the training periodization. Open Access J Sports Med. 2012;3:43-9.

23. Brunelli DT, Rodrigues A, Lopes WA, Gáspari AF, Bonganha V, Montagner PC, et al. Monitoring of immunological parameters in adolescent basketball athletes during and after a sports season. J Sports Sci. 2014;32(11):1050-9.

24. Yamada AK, Simões RA, César MC, Brunelli DT, Dias R, Frollini AB, et al. Adipokines levels in volleyball athletes following training periodization. Gazz Med Ital. 2014;173(7-8):401-7.

25. Turnbull AV, Rivier CL. Regulation of the hypothalamic-pituitary-adrenal axis by cytokines: actions and mechanisms of action. Physiol Rev. 1999;79(1):1-71.

26. Silverthorn DS. Fisiologia humana uma abordagem integrada. 2a ed. São Paulo: Manole; 2003.

27. McArdle DW, Katch IF, Katch LV. Fisiologia do exercício: energia, nutrição e desempenho humano. 6a ed. Rio de Janeiro: Guanabara Koogan; 2008.

28. Guyton AC, Hall JE. Tratado de fisiologia médica. 12a ed. Rio de Janeiro: Guanabara Koogan; 2011.

29. Nieman DC, Pedersen BK. Exercise and immune function. Recent developments. Sports Med. 1999;27(2):73-80.

30. Ferreira CKO, Prestes J, Frollini AB, Donatto FF, Dias R, Guereschi MG, et al. Influence of short duration acute exercise on the number, viability, functionality and apoptosis of neutrophils in sedentary rats. J Exerc Physiol Online. 2007;10(6):27-36.

31. Dias R, Frollini AB, Prestes J, Ferreira CKO, Donatto FF, Verlengia R, et al. Efeito do exercício agudo de curta duração em leucócitos circulantes e linfócitos teciduais de ratos. Rev Bras Educ Fís Esp. 2007;21(3):229-43.
32. Prestes J, Frollini AB, Guereschi M, Dias R, Donatto FF, Ferreira CKO, Foschini D, et al. Effects of two acute exercise sessions performed in the same day in different intensities on total leukocytes counting, circulating and tissue lymphocytes. Rev Atenção Saúde. 2007a;5(11):27-33.

33. Prestes J, Ferreira CKO, Frollini AB, Dias R, Donatto FF, Guereschi MG, et al. Influência do exercício físico agudo realizado até a exaustão sobre o número de leucócitos, linfócitos e citocinas circulantes. Fit Perf J. 2007;6(1):32-7.

34. Prestes J, Ferreira CK, Dias R, Frollini AB, Donatto FF, Cury-Boaventura MF, et al. Lymphocyte and cytokines after short periods of exercise. Int J Sports Med. 2008; 29(12):1010-4.

35. Prestes J, Frollini AB, Dias R, Guereschi MG, Ferreira CKO, Donatto FF, et al. Influência do exercício físico em diferentes intensidades sobre o número de leucócitos, linfócitos e citocinas circulantes. Rev Bras Med 2008;65(3):56-60.

36. Nieman DC. Does exercise alter immune function and respiratory infections? President's Council on Physical Fitness and Sports. Phys Fitness Sports. 2001;3(13):1-10.

37. Mujika I, Padilla S. Scientific bases for precompetition tapering strategies. Med Sci Sports Exerc 2003;35(7):1182-7.

38. Bosquet L, Montpetit J, Arvisais D, Mujika I. Effects of tapering on performance: a meta-analysis. Med Sci Sports Exerc. 2007;39(8):1358-65.

39. Mujika I. Polimento e maximização: para um ótimo desempenho físico; Barueri: Manole; 2012.

40. Foster, C. Monitoring training in athletes with reference to overtraining syndrome. Med Sci Sports Exerc. 1998;30(7):1164-8.

41. Gleeson M. Biochemical and immunological markers of over-training. J Sports Sci Med. 2002;1 (2):31-41.

42. Costa LOP, Samulski DM. Overtraining em atletas de alto nível - Uma Revisão Literária. R bras Ci e Mov. 2005;13(2):123-34.

43. Alves RN, Costa LOP, Samulski DM. Monitoramento e prevenção do supertreinamento em atletas. Rev Bras Med Esporte. 2006;12(5):291-6.

44. Meeusen R, Duclos M, Gleeson M, Rietjens G, Steinacker J, Urhausen A. Prevention, diagnosis and treatment of the overtraining syndrome. Eur J Sport Sci. 2006;6(1):1-14.

45. Araújo GG, Gobatto CA, Hirata RDC, Hirata MH, Cavaglieri CR, Verlengia R. Respostas fisiológicas para detectar o overtraining. Rev Educ Fís/UEM. 2008; 19(2):275-89.

46. Brooks KA, Carter JG. Overtraining, exercise, and adrenal insufficiency. J Nov Physiother. 2013;3(1):125.

47. Reid VL, Gleeson M, Williams N, Clancy RL. Clinical investigation of athletes with persistent fatigue and/or recurrent infections. J Nov Physiother. 2013;3(1):1-5.

48. Pyne DB, Gleeson M, McDonald WA, Clancy RL, Perry Jr C, Fricker PA. Training strategies to maintain immunocompetence in athletes. Int J Sports Med. 2000; 21(Supll 1):S51-60.

49. Nunes LAS, Lazarim FL, Brenzikofer R, Macedo DV. Applicability of the reference interval and reference change value of hematological and biochemical biomarkers to sport science. In. Kenneth R. Zaslav ed. Sports Med Sports Injury. Rijeka: InTech; 2012. p.77-98.

50. Nieman DC. Exercise, infection, and immunity. Int J Sports Med. 1994;15(Suppl 3): S131-41.

51. Malm C. Susceptibility to infections in elite athletes: the S-curve. Scand J Med Sci Sports. 2006;16(1):4-6.

52. Abbas AK, Lichtman AH. Imunologia básica funções e distúrbios do sistema imunológico. 2a ed. Rio de Janeiro: Elsevier; 2007

53. Pedersen BK, Fischer CP. Beneficial health effects of exercise - the role of IL-6 as a myokine. Trends Pharmacol Sci. 2007;28(4):152-6.

54. Tomiya A, Aizawa T, Nagatomi R, Sensui H, Kokubun S. Myofibers Express IL-6 after eccentric exercise. Am J Sports Med. 2004;32(2):503-8.

55. Petersen AMW, Pedersen BK. The anti-inflammatory effect of exercise. J Appl Physiol. 2005;98(4):1154-62.

56. Prestes J, Donatto FF, Dias R, Frollini AB, Cavaglieri CR. Papel da interlecina-6 como um sinalizador em diferentes tecidos durante o exercício físico. Fit Perf J. 2006;5(6):348-53.

57. Dias R, Frollini AB, Prestes J, Teixeira LFM, Cereja DMP, Baganha RJ, et al. Exercícios de força e parâmetros imunológicos: contagem leucocitária, inflamação e regeneração. R bras Ci e Mov. 2008;16(3):100-7.

58. Nemet D, Oh Y, Kim HS, Hill MA, Cooper DM. Effect of Intense exercise on inflammatory cytokines and growth mediators in adolescent boys. Pediatrics. 2002;110(4):681-9.

59. Garcia-Martinez C, Lopez-Soriano FJ, Argiles JM. Acute treatment with tumour necrosis factor-a induces changes in protein metabolism in rat skeletal muscle. Mol Cell Biochem. 1993;125(1):11-8.

60. Frost RA, Lang CH, Gelato MC. Transient exposure of human myoblasts to tumor necrosis factor-a inhibits serum and insulin-like growth factor-I stimulated protein synthesis. Endocrinology. 1997;138(10):4153-9. 